\title{
Hypertension as a Metabolic Disorder and the Novel Role of the Gut
}

\author{
Masami Tanaka ${ }^{1} \cdot$ Hiroshi Itoh ${ }^{1}$
}

Published online: 24 June 2019

(C) The Author(s) 2019

\begin{abstract}
Purpose of Review Hypertension is related to impaired metabolic homeostasis and can be regarded as a metabolic disorder. This review presents possible mechanisms by which metabolic disorders increase blood pressure (BP) and discusses the importance of the gut as a novel modulator of BP.

Recent Findings Obesity and high salt intake are major risk factors for hypertension. There is a hypothesis of "salt-induced obesity"; i.e., high salt intake may tie to obesity. Heightened sympathetic nervous system (SNS) activity, especially in the kidney and brain, increases BP in obese patients. Adipokines, including adiponectin and leptin, and renin-angiotensin-aldosterone system (RAAS) contribute to hypertension. Adiponectin induced by a high-salt diet may decrease sodium/glucose cotransporter (SGLT) 2 expression in the kidney, which results in reducing BP. High salt can change secretions of adipokines and RAAS-related components. Evidence has been accumulating linking the gastrointestinal tract to BP. Glucagon-like peptide-1 (GLP-1) and ghrelin decrease BP in both rodents and humans. The sweet taste receptor in enteroendocrine cells increases SGLT1 expression and stimulates sodium/glucose absorption. Roux-en-Y gastric bypass improves glycemic and BP control due to reducing the activity of SGLT1. Na/H exchanger isoform 3 (NHE3) increases BP by stimulating the intestinal absorption of sodium. Gastrin functions as an intestinal sodium taste sensor and inhibits NHE3 activity. Intestinal mineralocorticoid receptors also regulate sodium absorption and BP due to changing ENaC activity. Gastric sensing of sodium induces natriuresis, and gastric distension increases BP. Changes in the composition and function of gut microbiota contribute to hypertension. A high-salt/fat diet may disrupt the gut barrier, which results in systemic inflammation, insulin resistance, and increased BP. Gut microbiota regulates BP by secreting vasoactive hormones and short-chain fatty acids. BPlowering effects of probiotics and antibiotics have been reported. Bariatric surgery improves metabolic disorders and hypertension due to increasing GLP-1 secretion, decreasing leptin secretion and SNS activity, and changing gut microbiome composition. Strategies targeting the gastrointestinal system may be therapeutic options for improving metabolic abnormalities and reducing BP in humans. Summary SNS, brain, adipocytes, RAAS, the kidney, the gastrointestinal tract, and microbiota play important roles in regulating BP. Most notably, the gut could be a novel target for treatment of hypertension as a metabolic disorder.
\end{abstract}

Keywords Hypertension · Obesity · Salt · Sympathetic nervous activity · Adipokines · Renin-angiotensin-aldosterone system . Sodium/glucose cotransporter $\cdot$ Gastrointestinal tract $\cdot$ Microbiota

\section{Introduction}

Hypertension causes serious health problems if left uncontrolled [1]; it is the leading contributor to global

This article is part of the Topical Collection on Prevention of Hypertension: Public Health Challenges

Hiroshi Itoh

hiito@keio.jp

Masami Tanaka

tana176k@keio.jp

1 Division of Endocrinology, Metabolism and Nephrology, Department of Internal Medicine, Keio University School of Medicine, 35 Shinanomachi, Shinjuku-ku, Tokyo 160-8582, Japan disease burden [2, 3]. Hypertension often coexists with obesity, type 2 diabetes mellitus (DM), and dyslipidemia, referred to as metabolic syndrome. Hypertension with versus without metabolic abnormalities is associated with higher risk for cardiovascular events. Hence, the risk stratification of hypertension is based on the number and severity of metabolic risk factors [4]. Several guidelines, including the Japanese hypertension guideline JSH 2014, for the management of high BP use obesity, metabolic syndrome, DM, and dyslipidemia for risk stratification among hypertensive patients [5]. For hypertensive individuals with several metabolic abnormalities, rapid initiation and intensification of BPlowering therapy are strongly recommended. 
The number of adults with hypertension worldwide increased from 594 million in 1975 to 1.13 billion in 2015 [6]. In parallel, the prevalence of obesity worldwide increased more than three times in men and more than twice in women during the last four decades [7]. According to the Global Burden of Disease Study conducted in 195 countries, the prevalence of obesity in 2015 was estimated to be $12 \%$ in adults [8]. With increasing body mass index (BMI), the prevalence of hypertension, DM, and dyslipidemia increases in a linear fashion [9••]. Therefore, hypertension is considered one of the metabolic disorders.

\section{Interrelationships Between High Salt Intake, Obesity, and Hypertension}

The JSH 2014 strongly recommends that adults should consume less than $6 \mathrm{~g}$ of salt per day. However, salt intake is still high in Japan. The 2018 ESC/ESH guideline recommends that adults should consume less than $5 \mathrm{~g}$ of salt per day [10]. The 2017 AHA/ACC/ASH guideline defines optimal salt intake as consuming less than $1500 \mathrm{mg}$ sodium (3.8 g salt) per day [11].

High salt intake links not only to increased BP but also to obesity, i.e., "salt-induced obesity" (Table 1). A crosssectional study using a 7-day dietary record suggested significant associations between salt intake and sugarsweetened soft drink consumption in children [12]. However, salt-obesity association was independent of energy intake [13]. The results suggest that salt intake may contribute to obesity. In an experimental study, mice fed on a high-salt diet had increased protein catabolism in the liver and skeletal muscle and showed increased food intake [14]. The catabolized proteins are converted into urea, which increases water reabsorption in the kidney. The observed increased appetite of mice could be a compensatory response to the energy-intensive salt-driven protein catabolism process.

\section{Metabolic Abnormalities Associated with High Blood Pressure}

\section{Sympathetic Nervous System}

Greater sympathetic nervous system (SNS) activity precedes BP elevation in experimental and human studies [17]. Greater SNS activity, especially in the kidney, contributes to hypertension [18]. Renal SNS increases sodium reabsorption and renin secretion and impairs pressure natriuresis. Greater SNS activity also contributes to metabolic disorders. In patients with metabolic syndrome, SNS is activated due to hyperinsulinemia, hyperleptinemia, activated renin-angiotensin-aldosterone system (RAAS), baroreflex dysfunction, and obstructive sleep apnea $[19,20]$. High-fat and carbohydrate diets stimulate $\alpha 1-$ and $\beta$ adrenergic peripheral receptors [21]. Baroreflex, which inhibits SNS activity in a compensatory manner when BP rises, is impaired in obese hypertensives [22]. Central SNS activation, induced by hyperactivity of leptin and the preproopiomelanocortin pathway, is also related to obesity and hypertension [23].

Increased microglial activation and neuroinflammation within the brain regions that control autonomic response contribute to hypertension [24]. SNS activity is heightened by activation of brain regions controlling autonomic function due to high-fat diet, salt, stress, and angiotensin II (AngII) [25, 26]. The paraventricular nucleus of the hypothalamus (PVN) integrates inputs from the brainstem and circumventricular organs with the rostral ventrolateral medulla and intermediolateral nucleus in the spinal cord [27]. In the presence of hypertension, neuroinflammation is evident with activated microglia and immigrating bone marrow progenitors assembled in PVN [28, 29••, 30]. Epigenetic aberration of PVN AngII type 1 receptor (AT1), caused by DNA methyltransferase 3a, contributes to saltsensitive hypertension in rat offspring [31].

\section{Adipokines}

Adipocytes secrete a variety of bioactive substances, referred to as adipokines. Under physiological conditions, adipocytes

Table 1 Salt-induced obesity: observations and possible mechanisms

\begin{tabular}{|c|c|c|c|c|}
\hline Clinical/basic & Subjects & Observations & Possible mechanisms & Ref \\
\hline \multirow[t]{2}{*}{ Clinical studies } & Human & $\begin{array}{l}\text { Significant association between salt intake and sugar-sweetened } \\
\text { soft drink consumption }\end{array}$ & NA & {$[12]$} \\
\hline & Human & Significant association between salt intake and body fat mass & NA & {$[13]$} \\
\hline \multirow[t]{3}{*}{ Basic studies } & Mice & High salt intake induces increased food intake & Increased salt-driven protein catabolism & {$[14]$} \\
\hline & Mice & $\begin{array}{l}\text { Salt intake activates the reductase-fructokinase pathway in the } \\
\text { liver and hypothalamus, leading to endogenous fructose } \\
\text { production }\end{array}$ & Increased leptin resistance & {$[15]$} \\
\hline & Adipocytes & $\begin{array}{l}\text { High salt increases adipogenesis/lipogenesis and inflammatory } \\
\text { adipokines }\end{array}$ & Activation of salt-inducible kinase & {$[16 \bullet]$} \\
\hline
\end{tabular}

$B M I$ body mass index, $N A$ not available 
release anti-inflammatory adipokines including adiponectin, nitric oxide (NO), transforming growth factor (TGF)- $\beta$, and inerleukin-10, which improve insulin sensitivity and exert anti-atherosclerotic effect. However, in persons with metabolic disorders, adipocytes are hypertrophied and secrete proinflammatory adipokines including leptin, tumor necrosis factor- $\alpha$, angiotensinogen, and interleukin- 6 , which aggravate insulin resistance and exert pro-atherosclerotic effect [32].

Lower plasma levels of adiponectin and leptin are associated with higher BMI [33]. Lower plasma adiponectin levels are associated with hypertension and metabolic disorders. Adiponectin decreases the expression of sodium/glucose cotransporter (SGLT) 2 in the kidney [34•]. Obesity decreases adiponectin secretion, which leads to higher SGLT2 expression in obese than in non-obese persons. In contrast, a highsalt diet activates peroxisome proliferator-activated receptor $\delta$ and adiponectin production, leading to decreased renal SGLT2 expression and BP. This compensatory mechanism is impaired in persons with diabetes [34•].

Increased circulating leptin levels are present in animals and humans with hypertension [35]. Leptin crosses the blood-brain barrier, acts on the hypothalamus, and regulates energy metabolism via decreasing appetite and increasing energy expenditure with heightened SNS [36]. High salt intake has been reported to activate the aldose reductase-fructokinase pathway [15] and produce fructose in the liver and hypothalamus. Increased fructose contributes to leptin resistance, and this, in turn, leads to hyperphagia, insulin resistance, fatty liver, obesity, and hypertension.

\section{Renin-Angiotensin-Aldosterone System}

Obesity is associated with increased RAAS activity. RAAS exists within several organs, referred to as the tissue RAAS [37]. The brain, heart, kidney, immune cells, vasculature, and adipose tissue express all components of RAAS [38]. Adipocytes, especially intra-abdominal adipocytes, produce angiotensinogen and aldosterone. Urinary levels of aldosterone are associated with insulin resistance and are higher in overweight than in lean normotensive adults [39]. Soluble factors secreted from the adipose tissue, including complement-C1q TNF-related protein and leptin, increase aldosterone secretion from adrenocortical cells [40-42].

Salt intake may be associated with adipogenesis/ lipogenesis and inflammation via increasing the expression of adipokines and the RAAS-related components, including $\alpha$-adducin- 1 , cytochrome P450 family 11 -subfamily $\beta-2$, and mineralocorticoid receptor $\left[16^{\bullet}\right]$.

Reduced resting metabolic rate (RMR), which is partly determined by RAAS within the hypothalamus, is associated with obesity [43, 44]. AT1, agouti-related peptides (AgRP), and the leptin receptor (Lepr) are co-expressed on arcuate nucleus (ARC) cells in the hypothalamus. AT1 in the central nervous system increases energy expenditure, whereas AngII type 2 receptor in adipocytes reduces RMR [45, 46]; AT1 is expressed in a specific subset of AgRP neurons named SST3 [47, 48]. AT1 is activated via a variety of stimuli including leptin, high-fat diet, and deoxycorticosterone (DOCA)-salt and increases thermogenic SNS activity and RMR [49]. Thus, RAAS in the ARC may contribute to obesity-related hypertension.

\section{Gastrointestinal Tract and BP Regulation}

Salt, fat, and carbohydrates are absorbed through the gastrointestinal tract, and its dysfunction causes metabolic disorders (Fig. 1). Thus, the gastrointestinal tract may be regarded as the essential organ for metabolic syndrome and hypertension [50].

\section{Gut Hormones}

Several gut hormones contribute to vascular function and BP [51]. Chronic administration of glucagon-like peptide 1 (GLP1) improves endothelial dysfunction and reduces BP in Dahl salt-sensitive rats with a high-salt diet [52]. These effects are due to natriuretic effects of GLP1 that are attributable to changing renal hemodynamics and inhibiting $\mathrm{Na} / \mathrm{H}$ exchanger isoform 3 (NHE3) activities in the renal proximal tubule. BPlowering effects of GLP1 receptor agonists have been documented in meta-analysis of clinical trials [53].

Ghrelin, secreted mainly from the stomach, exerts an orexigenic effect including hunger sensation [54]. We demonstrated that ghrelin inhibited BP elevation and renal damage caused by AngII through an anti-oxidative stress mechanism in hypertensive mice [55]. In this study, ghrelin inhibited AngII-induced upregulations of TGF- $\beta$ and plasminogen activator inhibitor-1 in the kidney, which results in ameliorating renal fibrosis. Therefore, ghrelin is a contributor to BP regulation in the context of the gastrorenal axis [56]. Furthermore, ghrelin increased the expression of mitochondrial uncoupling protein 2 (UCP2) as well as $\mathrm{PGC} 1 \alpha$, a key regulator of mitochondrial biosynthesis. Ghrelin administration improved physical function in sarcopenia mice via mitochondrial activation and muscular enhancement [57].

\section{Taste Perception}

Salt taste sensitivity is related to salt consumption and thus may be associated with hypertension [58]. In Japanese women, impaired salt taste perception is associated with a higher prevalence of hypertension [59].

Taste perception is a sensory function of the gastrointestinal tract. Taste receptors are expressed on the taste buds in the tongue, the gut, and the brain [60]. Taste receptors in 


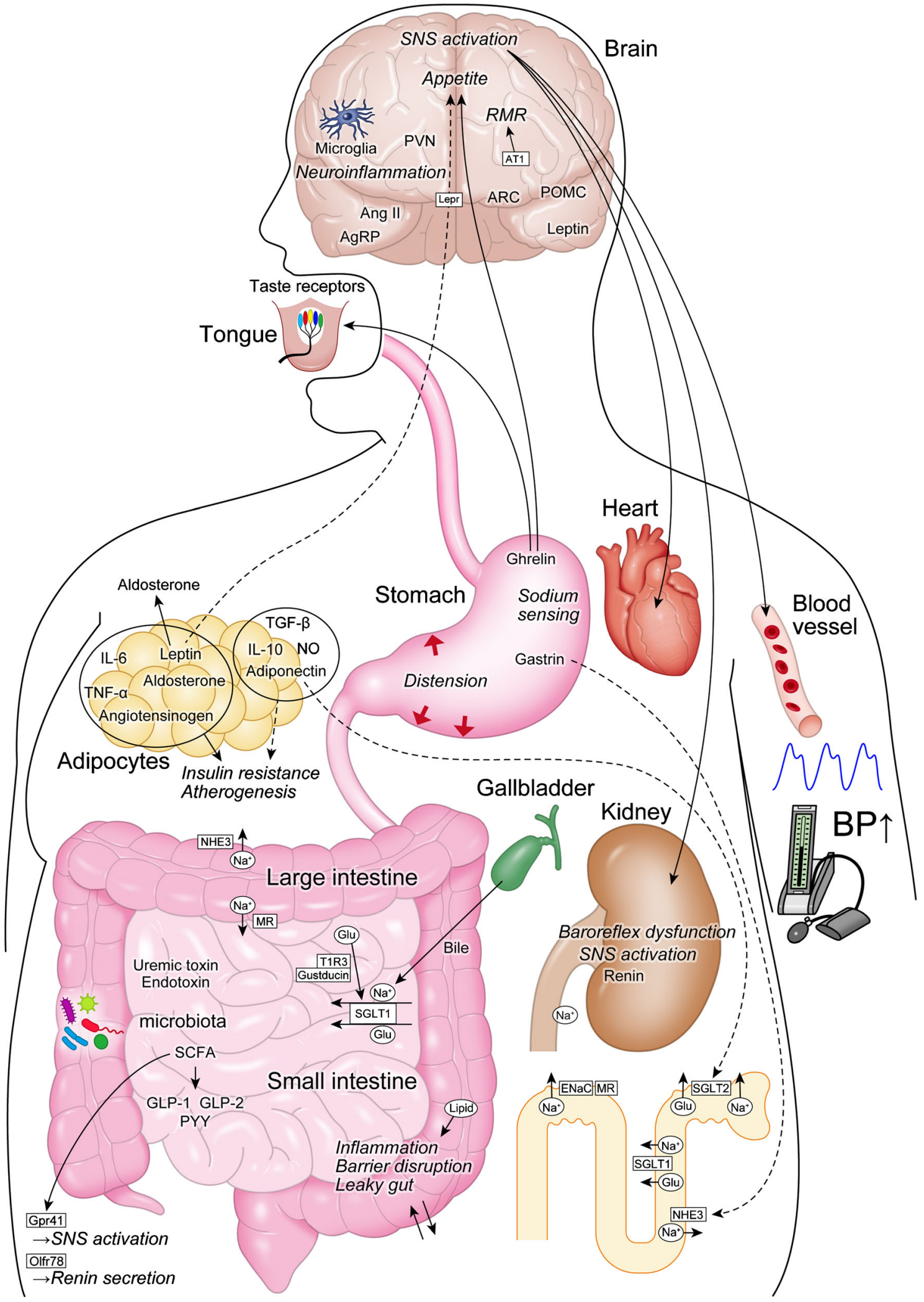

mammals, including the sweet taste receptor, are GTP-binding protein-coupled receptors (GPCRs). The salt taste receptor is supposed to be an epithelial sodium channel (ENaC), also called as an amiloride-sensitive sodium channel. 
Fig. 1 The gut, brain, and kidney play important roles in regulating blood pressure. Enhanced renal SNS induces sodium retention, increases renin secretion, and impairs pressure natriuresis. Central SNS is enhanced through increased microglial activation and neuroinflammation. Leptin acts on the hypothalamus and regulates energy metabolism by decreasing appetite and increasing energy expenditure. Adiponectin is induced by a high-salt diet and decreases the expression of SGLT2. AT1 in the brain stimulates thermogenic SNS activity, energy expenditure, and RMR. Low-pressure gastric distention raises blood pressure. Ghrelin exerts an orexigenic effect and increases taste sensitivity. Gastrin, whose secretion is stimulated by oral sodium intake, is reabsorbed by renal proximal tubules and inhibits NHE3 activity. T1R3 and gustducin act as sweet taste receptors in the intestine. When they sense sugar/sweetener, they increase the expression of SGLT1. Intestinal MR modulates ENaC activity and regulates sodium absorption. Sodium in the bile is required for the proper function of SGLT1 in the intestine. Gut microbiota produces both pro-inflammatory mediators, such as uremic toxin, and anti-inflammatory mediators, such as SCFA. SCFA stimulates the secretion of anti-inflammatory gut hormones, such as GLP-1 from the enteroendocrine cells. High-salt and high-fat diets alter the microbial composition and induce intestinal inflammation and gut barrier disruption, leading to the leaky gut mucosa. AgRP agouti-related peptide, AngII angiotensin II, ARC arcuate nucleus, AT1 angiotensin II type-1 receptor, BP blood pressure, $\mathrm{ENaC}$ epithelial sodium channel, GLP glucagon-like peptide, Glu glucose, IL interleukin, Lepr leptin receptor, MR mineralocorticoid receptor, Na sodium, NHE3 Na/H exchanger isoform 3, NO nitric oxide, POMC preproopiomelanocortin, PVN paraventricular nucleus, PYY peptide YY, RMR resting metabolic rate, SCFA short-chain fatty acid, SGLT sodium/glucose cotransporter, SNS sympathetic nervous system, TGF transforming growth factor, TNF tumor necrosis factor

Luminal sugar/sweetener sensors in the intestine include the sweet-responsive type 1 taste receptor subunit 3 (T1R3) and the taste $\mathrm{G}$ protein gustducin. When intestinal sugar/ artificial sweetener sensors are activated, SGLT1 mRNA and protein expression and glucose-absorptive capacity are increased [61•]. SGLT1 is a major pathway of transporting dietary sugars from the intestinal lumen into the enterocytes. SGLT1 is a $\mathrm{Na}^{+}$/glucose cotransporter, and thus sodium and glucose are absorbed concomitantly, which may result in increased BP. SGLT1 inhibitors such as phlorizin may reduce not only glucose but also BP.

Taste perception is modulated by many vasoactive and gastric hormones. The nervous system associated with the amiloride-sensitive salt taste receptors is impaired in aldosterone/sodium chloride-induced hypertensive rats [62]. AngII increases sodium intake via attenuating the sensitivity of the amiloride-sensitive salt taste receptor and increases energy intake via enhancing sweet taste sensitivity in mice [63]. Salt and lipid taste sensitivity is attenuated in ghrelinknockout mice [64].

\section{Intestinal Sodium Absorption}

NHE3-knockout mice have lower BP than the control mice [65]. Pharmacologic inhibition of the gut NHE3 prevents hypertension in animals and humans through inhibiting intestinal sodium absorption [66].

Gastrin is secreted from $\mathrm{G}$ cells in the stomach and duodenum, and its secretion is upregulated by an oral sodium intake. Gastrin is reabsorbed at the renal proximal tubules [67] and has a natriuretic effect via inhibiting renal sodium transport through the cholecystokinin type B receptor (CCKBR) on several nephron segments [68]. Gastrin inhibits the activities of NHE3 [69] and $\mathrm{Na}^{+}, \mathrm{K}^{+}$-ATPase [70] in renal proximal tubule cells. Gastrin inhibits sodium transport in the intestine due to stimulating cholinergic nerves or inhibiting sympathetic nerves [56]. Gastrin can be regarded as an intestinal sodium taste sensor. The CCKBR antagonist reduces natriuresis in salt-resistant mice with a high-salt diet [71]. Germline deletion of gastrin [56] and CCKBR [71] in mice reduces sodium excretion after an oral sodium load, i.e., salt-sensitive hypertension.

The mineralocorticoid receptor (MR) is expressed on the epithelial cells in the renal tubules, intestine, and skin. Renal MR regulates sodium balance through sodium absorption in the kidney. We investigated the function of MR in the intestine using intestinal epithelial cell-specific MR-knockout (IECMR KO) mice [72•] (Fig. 2). IEC-MR KO mice fed on a standard diet had increased fecal sodium excretion with reduced colonic expression of $\beta$ - and $\gamma$-ENaC. DOCA/salt-induced BP elevation was also attenuated in IEC-MR KO mice.

Net sodium absorption in the small intestine is increased in spontaneously hypertensive rats (SHRs) [73]. The aberrant expression and function of SGLT1 in the jejunal epithelium of SHRs have been reported [74]. Baud et al. reported that the glucose uptake in the bile-deprived alimentary limb (AL) in the intestine was reduced after conducting Roux-en-Y gastric bypass (RYGB) in minipigs [75•]. When bile or sodium was added to AL, glucose uptake was restored that was blocked by the SGLT1 inhibitor phlorizin. The decrease in glucose uptake in the intestine after RYGB has been observed in humans. The glucose- and BP-lowering effects of RYGB may be attributable to reducing activity of SGLT1.

\section{Gastric Sodium/Volume Sensor}

RYGB improved diurnal diuresis in morbidly obese patients [76]. Although patients with RYGB tend to increase salt intake, their office BPs were not elevated [77]. The observed increased salt intake in patients with RYGB may be due to a compensation for natriuresis or a change in salt appetite after the intervention. An experimental study suggested that gastric sodium sensors regulate salt appetite and have natriuretic effects in response to food and water ingestion [78]. RYGB may modify the effects of gastric sodium sensors.

Pressure-induced gastric distention increases both heart rate and BP in anesthetized rats. Gastric distension affects the splanchnic nerve systems, and this, in turn, activates the 
Fecal sodium

( $\mu \mathrm{mol} / 24 \mathrm{hr}$ )

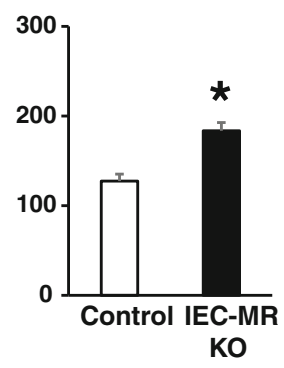

Colonic expression of $\gamma$-ENaC

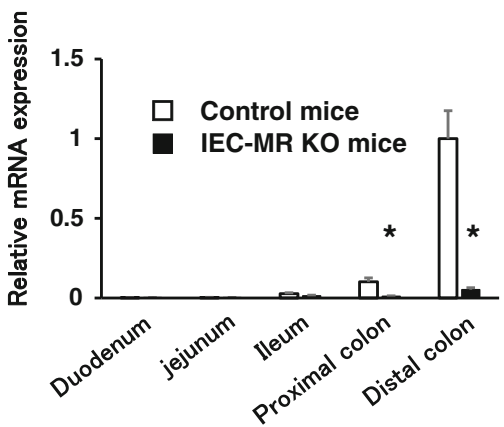

Changes in blood pressure by DOCA/salt administration

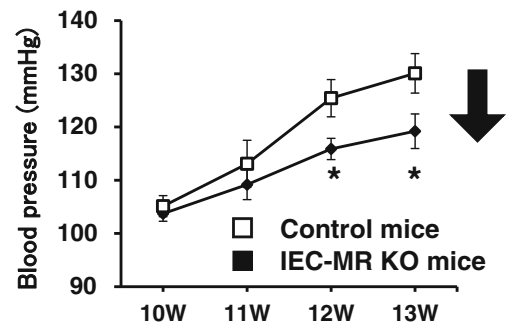

Fig. 2 The effect of intestinal mineralocorticoid receptor knockout on fecal sodium, $\gamma$-ENaC expression, and blood pressure. $* P<0.05$ versus control. Adapted from [72•]. DOCA deoxycorticosterone, ENaC

nucleus of the solitary tract, nucleus ambiguous, lateral reticular nucleus, and ventrolateral medulla [79]. The pressor response is attenuated after splanchnic denervation.

\section{Gut Microbiota}

\section{High Salt/Fat Intake and Microbiota}

Changes in the composition and function of the gut microbiota contribute to cardiometabolic diseases, including hypertension, obesity, type 2 DM, and dyslipidemia [19]. When microbiota from mice with metabolic syndrome or mice genetically deficient in Toll-like receptor 5 was transferred to the germ-free wild-type mice, the wild-type mice exhibited metabolic syndrome including insulin resistance, obesity, dyslipidemia, and hypertension [80].

Most Proteobacteria and some Firmicutes family produce pro-inflammatory uremic toxins [81, 82], while Lactobacilli produce anti-inflammatory mediators, including short-chain fatty acid (SCFA) and NO [83, 84]. SCFAs increase antiinflammatory gut hormones, including GLP-1, GLP-2, and PYY from enteroendocrine cells [83].

A high-salt diet changes the microbial composition; e.g., fecal SCFA (acetate, propionate, and isobutyrate) production is increased in Dahl salt-sensitive rats [85•]. In this study, differences in microbial composition were present between the mice fed on normal- and high-salt diets, and the abundance of seven microbial taxa was associated with BP. It was also reported that high-salt diet aggravated colitis due to changing fecal microbiota composition in mice [86•]. In the experimental murine colitis model, the relative abundance of Lactobacillus and levels of the butyrate (protective SCFA) were reduced, which results in a pro-inflammatory state in the gut.

A high-fat diet also affects the microbial composition and function [87]. A high-fat diet increases intestinal inflammation and disrupts the gut barrier, which makes the gut mucosa epithelial sodium channel, IEC-MR KO intestinal epithelial cell-specific mineralocorticoid receptor knockout, W weeks

leaky. Bacterial endotoxins generated by gut microbiota pass the mucosal tissue and enter into the systemic circulation if the intestinal barrier was disrupted [88]. Therefore, the leaky gut mucosa induced by a fatty diet leads to inflammation [89], insulin resistance, reducing glucose uptake, and hepatic glucose production in vivo.

Using the macrophage-specific chemokine receptor 2knockout and IEC-specific tamoxifen-inducible Ccl2knockout mice [90••], we reported that a high-fat diet increased $\mathrm{Ccl} 2$ expression in the IECs that results in the recruitment of pro-inflammatory macrophages, increased gut permeability, inflammasome activation, and insulin resistance in the adipose tissue.

Oral administration of Akkermansia (A) muciniphila improves the gut barrier dysfunction and metabolic disorders in obese and type 2 diabetic mice [91]. Higher abundance of A. muciniphila is observed to be significantly associated with the improvement of cardiometabolic parameters in obese individuals undergoing caloric restriction [92]. Treatment with live or pasteurized A. muciniphila had no adverse effects in humans [93•], suggesting the potential novel treatment for metabolic disorders in humans.

\section{Gut Microbiota and Hypertension}

Emerging evidence indicates that the gut microbiota contributes to hypertension [94]. Gut microbiota generates vasoactive hormones including dopamine, norepinephrine, and serotonin [51]. Gut dysbiosis has been present in both animals [95] and humans with hypertension [96]. Firmicutes and A. muciniphila decrease while Bacteroidetes increases in rodents and humans with hypertension [94, 96, 97]. The ratio of Firmicutes to Bacteroidetes may be associated with hypertension.

Deletion of NHE3 changes gut microbiota composition and attenuates BP elevation in mice infused with AngII [65, 98]. SCFAs, including acetate, propionate, and butyrate, are 
produced by the interaction between dietary fiber and microbiota and enter into the systemic circulation. SCFAs bind to GPCRs, including Gpr41, Gpr43, Olfr78, and Gpr109a [99], and regulate BP. For example, SCFAs increase SNS activity via binding to GPR41 and increase renin secretion through Olfr78. Conversely, SCFAs induce vasodilation via binding to Gpr43 and Gpr109a [100]. Therefore, modifying gut microbiota using probiotics and antibiotics may be a possible target for regulating BP. A meta-analysis study demonstrated that probiotics reduce systolic BP by $3.56 \mathrm{mmHg}$ and diastolic BP by $2.38 \mathrm{mmHg}$ in 543 adults with or without hypertension [101].

Administration of minocycline changed microbiota composition and lowered BP in hypertensive rats infused with AngII [94]. Minocycline, neomycin, and vancomycin have been shown to increase systolic BP in Dahl salt-sensitive hypertensive rats. However, minocycline and vancomycin decreased while neomycin did not change systolic BP in SHR [102]. The inconsistent results suggest that the differences in genetic factors and gut microbiome may influence the effect of antibiotics on BP. Furthermore, minocycline reduces microglial activation and neuroinflammation in the brain, which improved dysbiosis and hypertension [94, 103]. In experimental studies using two hypertensive rats (rat infused with chronic low-dose AngII and SHR), the administration of CMT-3 (chemically modified tetracycline-3) into the cerebral ventricle inhibited AngII-induced activation of microglia and pro-inflammatory cytokines in the PVN of the hypothalamus [29••]. Intracerebroventricular CMT-3 administration also attenuates BP elevation and SNS activity in rats infused with AngII due to improving dysbiosis and pathological alterations (thickening of the muscular layer, increased areas of fibrosis, decreased goblet cell number, and shortening of villi) in the gut wall. These results suggest an effect of microglia and microbiota on BP, and antibiotics may be effective for controlling hypertension.

\section{Gastrointestinal Bypass Surgery}

Gastrointestinal bypass or metabolic surgery improves metabolic abnormalities in persons with morbid obesity. Diabetes, hypertension, hyperlipidemia, and obstructive sleep apnea were substantially improved after the intervention [50]. Although BP reduction after gastrointestinal bypass surgery is attributable to weight loss, BP reduction is observed before body weight reduction [104]. Therefore, the BP-lowering effect of the surgery may be independent of weight loss. The potential mechanisms underlying the BP-lowering effects of bypass surgery include increased secretion of gut hormones, including GLP-1 and PYY [105], decreasing leptin levels [106], increasing urinary sodium excretion [107], change in gut microbiota [108], and reducing SNS activity [109].

\section{Conclusion}

Hypertension often coexists with metabolic abnormalities. Shared underlying mechanisms between hypertension and metabolic abnormalities may be present, including altered gut hormones, intestinal sodium absorption, and gut microbiota. Strategies targeting the gastrointestinal system may be therapeutic options for improving metabolic abnormalities and reducing BP in humans.

\section{Compliance with Ethical Standards}

Conflict of Interest The authors declare no conflicts of interest relevant to this manuscript.

Human and Animal Rights and Informed Consent This article does not contain any studies with human or animal subjects performed by any of the authors.

Open Access This article is distributed under the terms of the Creative Commons Attribution 4.0 International License (http:// creativecommons.org/licenses/by/4.0/), which permits unrestricted use, distribution, and reproduction in any medium, provided you give appropriate credit to the original author(s) and the source, provide a link to the Creative Commons license, and indicate if changes were made.

\section{References}

Papers of particular interest, published recently, have been highlighted as:

- Of importance

•- Of major importance

1. Mozaffarian D, Benjamin EJ, Go AS, Arnett DK, Blaha MJ, Cushman M, et al. Heart disease and stroke statistics-2015 update: a report from the American Heart Association. Circulation. 2015;131(4):e29-322.

2. Poulter NR, Prabhakaran D, Caulfield M. Hypertension. Lancet. 2015;386(9995):801-12.

3. Demisse AG, Greffie ES, Abebe SM, Bulti AB, Alemu S, Abebe $\mathrm{B}$, et al. High burden of hypertension across the age groups among residents of Gondar city in Ethiopia: a population based cross sectional study. BMC Public Health. 2017;17(1):647.

4. Dekker JM, Girman C, Rhodes T, Nijpels G, Stehouwer CD, Bouter LM, et al. Metabolic syndrome and 10-year cardiovascular disease risk in the Hoorn Study. Circulation. 2005;112(5):666-73.

5. Shimamoto K, Ando K, Fujita T, Hasebe N, Higaki J, Horiuchi M, et al. The Japanese Society of Hypertension guidelines for the management of hypertension (JSH 2014). Hypertens Res. 2014;37(4):253-390.

6. NCD Risk Factor Collaboration (NCD-RisC). Worldwide trends in blood pressure from 1975 to 2015: a pooled analysis of 1479 population-based measurement studies with 19.1 million participants. Lancet 2017;389(10064):37-55.

7. NCD Risk Factor Collaboration (NCD-RisC). Trends in adult body-mass index in 200 countries from 1975 to 2014: a pooled analysis of 1698 population-based measurement studies with 19.2 million participants. Lancet 2016;387(10026):1377-1396. 
8. Afshin A, Forouzanfar MH, Reitsma MB, Sur P, Estep K, Lee A, et al. Health effects of overweight and obesity in 195 countries over 25 years. N Engl J Med. 2017;377(1):13-27.

9.• Kuwabara M, Kuwabara R, Niwa K, Hisatome I, Smits G, Roncal-Jimenez CA, et al. Different risk for hypertension, diabetes, dyslipidemia, and hyperuricemia according to level of body mass index in Japanese and American subjects. Nutrients 2018;10(8):1011. https://doi.org/10.3390/nu10081011. This epidemiological study clearly shows that obesity and overweight is an independent risk factor for hypertension, diabetes, dyslipidemia and hyperuricemia in both Japan and the U.S.

10. Williams B, Mancia G, Spiering W, Agabiti Rosei E, Azizi M, Burnier M, et al. 2018 ESC/ESH guidelines for the management of arterial hypertension: the Task Force for the management of arterial hypertension of the European Society of Cardiology and the European Society of Hypertension. J Hypertens. 2018;36(10): 1953-2041.

11. Whelton PK, Carey RM, Aronow WS, Casey DE Jr, Collins KJ, Dennison Himmelfarb C, et al. 2017 ACC/AHA/AAPA/ABC/ $\mathrm{ACPM} / \mathrm{AGS} / \mathrm{APhA} / \mathrm{ASH} / \mathrm{ASPC} / \mathrm{NMA} / \mathrm{PCNA}$ guideline for the prevention, detection, evaluation, and management of high blood pressure in adults: a report of the American College of Cardiology/ American Heart Association Task Force on Clinical Practice Guidelines. Hypertension. 2018;71(6):e13-e115.

12. He FJ, Marrero NM, MacGregor GA. Salt intake is related to soft drink consumption in children and adolescents: a link to obesity? Hypertension. 2008;51(3):629-34.

13. Ma Y, He FJ, MacGregor GA. High salt intake: independent risk factor for obesity? Hypertension. 2015;66(4):843-9.

14. Kitada K, Daub S, Zhang Y, Klein JD, Nakano D, Pedchenko T, et al. High salt intake reprioritizes osmolyte and energy metabolism for body fluid conservation. J Clin Invest. 2017;127(5):1944-59.

15. Lanaspa MA, Kuwabara M, Andres-Hernando A, Li N, Cicerchi C, Jensen T, et al. High salt intake causes leptin resistance and obesity in mice by stimulating endogenous fructose production and metabolism. Proc Natl Acad Sci U S A. 2018;115(12):3138-43.

16. Lee M, Sorn SR, Lee Y, Kang I. Salt induces adipogenesis/ lipogenesis and inflammatory adipocytokines secretion in adipocytes. Int J Mol Sci 2019;20(1). https://doi.org/10.3390/ ijms 20010160 . This in vitro study using salt-loading adipocytes suggests a possible link between obesity and high salt intake. Crosstalk between the Akt/mTOR and MERK/ERK might explain this link.

17. Oliveira-Sales EB, Colombari E, Abdala AP, Campos RR, Paton JF. Sympathetic overactivity occurs before hypertension in the two-kidney, one-clip model. Exp Physiol. 2016;101(1):67-80.

18. Grassi G, Mark A, Esler M. The sympathetic nervous system alterations in human hypertension. Circ Res. 2015;116(6):976-90.

19. DeMarco VG, Aroor AR, Sowers JR. The pathophysiology of hypertension in patients with obesity. Nat Rev Endocrinol. 2014;10(6):364-76.

20. Seravalle G, Grassi G. Sympathetic nervous system, hypertension, obesity and metabolic syndrome. High Blood Press Cardiovasc Prev. 2016;23(3):175-9.

21. Lambert EA, Straznicky NE, Dixon JB, Lambert GW. Should the sympathetic nervous system be a target to improve cardiometabolic risk in obesity? Am J Physiol Heart Circ Physiol. 2015;309(2): $\mathrm{H} 244-58$.

22. Thorp AA, Schlaich MP. Relevance of sympathetic nervous system activation in obesity and metabolic syndrome. J Diabetes Res. 2015;2015:341583.

23. Guarino D, Nannipieri M, Iervasi G, Taddei S, Bruno RM. The role of the autonomic nervous system in the pathophysiology of obesity. Front Physiol. 2017;8:665.
24. Haspula D, Clark MA. Neuroinflammation and sympathetic overactivity: mechanisms and implications in hypertension. Auton Neurosci. 2018;210:10-7.

25. Santisteban MM, Kim S, Pepine CJ, Raizada MK. Brain-gut-bone marrow axis: implications for hypertension and related therapeutics. Circ Res. 2016;118(8):1327-36.

26. Yang T, Richards EM, Pepine CJ, Raizada MK. The gut microbiota and the brain-gut-kidney axis in hypertension and chronic kidney disease. Nat Rev Nephrol. 2018;14(7):442-56.

27. Myers B, Scheimann JR, Franco-Villanueva A, Herman JP. Ascending mechanisms of stress integration: implications for brainstem regulation of neuroendocrine and behavioral stress responses. Neurosci Biobehav Rev. 2017;74(Pt B):366-75.

28. Kim S, Zingler M, Harrison JK, Scott EW, Cogle CR, Luo D, et al. Angiotensin II regulation of proliferation, differentiation, and engraftment of hematopoietic stem cells. Hypertension. 2016;67(3):574-84.

29.• Sharma RK, Yang T, Oliveira AC, Lobaton GO, Aquino V, Kim S, et al. Microglial cells impact gut microbiota and gut pathology in angiotensin II-induced hypertension. Circ Res. 2019;124(5):72736 This study is the first to suggest a link between microglia and microbiota, supporting the presence of a "gut-brain axis.".

30. Zubcevic J, Santisteban MM, Perez PD, Arocha R, Hiller H, Malphurs WL, et al. A single angiotensin II hypertensive stimulus is associated with prolonged neuronal and immune system activation in Wistar-Kyoto rats. Front Physiol. 2017;8:592.

31. Kawakami-Mori F, Nishimoto M, Reheman L, Kawarazaki W, Ayuzawa N, Ueda K, et al. Aberrant DNA methylation of hypothalamic angiotensin receptor in prenatal programmed hypertension. JCI Insight. 2018;3(21). https://doi.org/10.1172/jci.insight.95625.

32. Leggio M, Lombardi M, Caldarone E, Severi P, D'Emidio S, Armeni M, et al. The relationship between obesity and hypertension: an updated comprehensive overview on vicious twins. Hypertens Res. 2017;40(12):947-63.

33. Hall JE, do Carmo JM, da Silva AA, Wang Z, Hall ME. Obesityinduced hypertension: interaction of neurohumoral and renal mechanisms. Circ Res. 2015;116(6):991-1006.

34. Zhao Y, Gao P, Sun F, Li Q, Chen J, Yu H, et al. Sodium intake regulates glucose homeostasis through the PPARdelta/ adiponectin-mediated SGLT2 pathway. Cell Metab. 2016;23(4): 699-711 This study highlights the SGLT2 glucose transporter as a possible safeguard against salt-induced hypertension.

35. Simonds SE, Pryor JT, Ravussin E, Greenway FL, Dileone R, Allen AM, et al. Leptin mediates the increase in blood pressure associated with obesity. Cell. 2014;159(6):1404-16.

36. Tang-Christensen M, Havel PJ, Jacobs RR, Larsen PJ, Cameron JL. Central administration of leptin inhibits food intake and activates the sympathetic nervous system in rhesus macaques. J Clin Endocrinol Metab. 1999;84(2):711-7.

37. Dzau V. The cardiovascular continuum and renin-angiotensinaldosterone system blockade. J Hypertens Suppl. 2005;23(1): S9-17.

38. Frigolet ME, Torres N, Tovar AR. The renin-angiotensin system in adipose tissue and its metabolic consequences during obesity. J Nutr Biochem. 2013;24(12):2003-15.

39. Bentley-Lewis R, Adler GK, Perlstein T, Seely EW, Hopkins PN, Williams GH, et al. Body mass index predicts aldosterone production in normotensive adults on a high-salt diet. J Clin Endocrinol Metab. 2007;92(11):4472-5.

40. Dinh Cat AN, Friederich-Persson M, White A, Touyz RM. Adipocytes, aldosterone and obesity-related hypertension. J Mol Endocrinol. 2016;57(1):F7-F21.

41. Huby AC, Antonova G, Groenendyk J, Gomez-Sanchez CE, Bollag WB, Filosa JA, et al. Adipocyte-derived hormone leptin is a direct regulator of aldosterone secretion, which promotes endothelial dysfunction and cardiac fibrosis. Circulation. 2015;132(22):2134-45. 
42. Jeon JH, Kim KY, Kim JH, Baek A, Cho H, Lee YH, et al. A novel adipokine CTRP1 stimulates aldosterone production. FASEB J. 2008;22(5):1502-11.

43. Fothergill E, Guo J, Howard L, Kerns JC, Knuth ND, Brychta R, et al. Persistent metabolic adaptation 6 years after "The Biggest Loser" competition. Obesity (Silver Spring). 2016;24(8):1612-9.

44. Deng G, Grobe JL. The renin-angiotensin system in the arcuate nucleus controls resting metabolic rate. Curr Opin Nephrol Hypertens. 2019;28(2):120-7.

45. Grobe JL, Buehrer BA, Hilzendeger AM, Liu X, Davis DR, Xu D, et al. Angiotensinergic signaling in the brain mediates metabolic effects of deoxycorticosterone (DOCA)-salt in C57 mice. Hypertension. 2011;57(3):600-7.

46. Littlejohn NK, Keen HL, Weidemann BJ, Claflin KE, Tobin KV, Markan KR, et al. Suppression of resting metabolism by the angiotensin AT2 receptor. Cell Rep. 2016;16(6):1548-60.

47. Romanov RA, Zeisel A, Bakker J, Girach F, Hellysaz A, Tomer R, et al. Molecular interrogation of hypothalamic organization reveals distinct dopamine neuronal subtypes. Nat Neurosci. 2017;20(2):176-88.

48. Campbell JN, Macosko EZ, Fenselau H, Pers TH, Lyubetskaya A, Tenen D, et al. A molecular census of arcuate hypothalamus and median eminence cell types. Nat Neurosci. 2017;20(3):484-96.

49. Claflin KE, Sandgren JA, Lambertz AM, Weidemann BJ, Littlejohn NK, Burnett CM, et al. Angiotensin AT1A receptors on leptin receptor-expressing cells control resting metabolism. J Clin Invest. 2017;127(4):1414-24.

50. Zhu Z, Xiong S, Liu D. The gastrointestinal tract: an initial organ of metabolic hypertension? Cell Physiol Biochem. 2016;38(5): 1681-94.

51. Afsar B, Vaziri ND, Aslan G, Tarim K, Kanbay M. Gut hormones and gut microbiota: implications for kidney function and hypertension. J Am Soc Hypertens. 2016;10(12):954-61.

52. Yu M, Moreno C, Hoagland KM, Dahly A, Ditter K, Mistry M, et al. Antihypertensive effect of glucagon-like peptide 1 in Dahl salt-sensitive rats. J Hypertens. 2003;21(6):1125-35.

53. Htike ZZ, Zaccardi F, Papamargaritis D, Webb DR, Khunti K, Davies MJ. Efficacy and safety of glucagon-like peptide-1 receptor agonists in type 2 diabetes: a systematic review and mixed-treatment comparison analysis. Diabetes Obes Metab. 2017;19(4):524-36.

54. Murray CD, Kamm MA, Bloom SR, Emmanuel AV. Ghrelin for the gastroenterologist: history and potential. Gastroenterology. 2003;125(5):1492-502.

55. Fujimura K, Wakino S, Minakuchi H, Hasegawa K, Hosoya K, Komatsu M, et al. Ghrelin protects against renal damages induced by angiotensin-II via an antioxidative stress mechanism in mice. PLoS One. 2014;9(4):e94373.

56. Jose PA, Yang Z, Zeng C, Felder RA. The importance of the gastrorenal axis in the control of body sodium homeostasis. Exp Physiol. 2016;101(4):465-70.

57. Tamaki M, Miyashita K, Hagiwara A, Wakino S, Inoue H, Fujii K, et al. Ghrelin treatment improves physical decline in sarcopenia model mice through muscular enhancement and mitochondrial activation. Endocr J. 2017;64(Suppl):S47-51.

58. Rabin M, Poli de Figueiredo CE, Wagner MB, Antonello ICF. Salt taste sensitivity threshold and exercise-induced hypertension. Appetite. 2009;52(3):609-13.

59. Michikawa T, Nishiwaki Y, Okamura T, Asakura K, Nakano M, Takebayashi $\mathrm{T}$. The taste of salt measured by a simple test and blood pressure in Japanese women and men. Hypertens Res. 2009;32(5):399-403.

60. Hamr SC, Wang B, Swartz TD, Duca FA. Does nutrient sensing determine how we "see" food? Curr Diab Rep. 2015;15(6):604.

61. Margolskee RF, Dyer J, Kokrashvili Z, Salmon KS, Ilegems E, Daly K, et al. T1R3 and gustducin in gut sense sugars to regulate expression of Na+-glucose cotransporter 1. Proc Natl Acad Sci U
S A. 2007;104(38):15075-80 This study is the first to show that the sweet taste receptor subunit T1R3 and the taste $G$ protein gustducin are the luminal sugar/sweetener sensors, regulating the expression of SGLT1.

62. Sakamoto T, Fujii A, Saito N, Kondo H, Ohuchi A. Alteration of amiloride-sensitive salt taste nerve responses in aldosterone $/ \mathrm{NaCl}$ induced hypertensive rats. Neurosci Res. 2016;108:60-6.

63. Shigemura N, Iwata S, Yasumatsu K, Ohkuri T, Horio N, Sanematsu K, et al. Angiotensin II modulates salty and sweet taste sensitivities. J Neurosci. 2013;33(15):6267-77.

64. Cai H, Cong WN, Daimon CM, Wang R, Tschop MH, Sevigny J, et al. Altered lipid and salt taste responsivity in ghrelin and GOAT null mice. PLoS One. 2013;8(10): 76553.

65. Li XC, Shull GE, Miguel-Qin E, Chen F, Zhuo JL. Role of the $\mathrm{Na}+\mathrm{H}+$ exchanger 3 in angiotensin II-induced hypertension in NHE3-deficient mice with transgenic rescue of NHE3 in small intestines. Physiol Rep. 2015;3(11):e12605.

66. Spencer AG, Labonte ED, Rosenbaum DP, Plato CF, Carreras $\mathrm{CW}$, Leadbetter MR, et al. Intestinal inhibition of the $\mathrm{Na}+\mathrm{H}+$ exchanger 3 prevents cardiorenal damage in rats and inhibits Na+ uptake in humans. Sci Transl Med. 2014;6(227):227ra36.

67. Melis M, Krenning EP, Bernard BF, Barone R, Visser TJ, de Jong M. Localisation and mechanism of renal retention of radiolabelled somatostatin analogues. Eur J Nucl Med Mol Imaging. 2005;32(10):1136-43.

68. von Schrenck T, Ahrens M, de Weerth A, Bobrowski C, Wolf G, Jonas L, et al. CCKB/gastrin receptors mediate changes in sodium and potassium absorption in the isolated perfused rat kidney. Kidney Int. 2000;58(3):995-1003.

69. Liu T, Jose PA. Gastrin induces sodium-hydrogen exchanger 3 phosphorylation and mTOR activation via a phosphoinositide 3kinase-/protein kinase C-dependent but AKT-independent pathway in renal proximal tubule cells derived from a normotensive male human. Endocrinology. 2013;154(2):865-75.

70. Liu T, Konkalmatt PR, Yang Y, Jose PA. Gastrin decreases Na+, $\mathrm{K}+$-ATPase activity via a PI 3-kinase- and PKC-dependent pathway in human renal proximal tubule cells. Am J Physiol Endocrinol Metab. 2016;310(7):E565-71.

71. Jiang X, Chen W, Liu X, Wang Z, Liu Y, Felder RA, et al. The synergistic roles of cholecystokinin B and dopamine D5 receptors on the regulation of renal sodium excretion. PLoS One. 2016;11(1):e0146641.

72. Nakamura T, Kurihara I, Kobayashi S, Yokota K, Murai-Takeda A, Mitsuishi Y et al. Intestinal mineralocorticoid receptor contributes to epithelial sodium channel-mediated intestinal sodium absorption and blood pressure regulation. J Am Heart Assoc 2018;7(13). https:/doi. org/10.1161/JAHA.117.008259. This study reveals the significance of intestinal mineralocorticoid receptors in sodium balance and blood pressure regulation.

73. Lubcke R, Barbezat GO. Intestinal ion transport in rats with spontaneous arterial hypertension. Clin Sci (Lond). 1988;75(2):127-33.

74. Sanchez-Aguayo I, Torreblanca J, de La Hermosa ML, Mate A, Planas JM, Vazquez CM. Ultrastructural and functional changes in the jejunal epithelium of spontaneously hypertensive rats. Life Sci. 2001;68(18):2105-13.

75. Baud G, Daoudi M, Hubert T, Raverdy V, Pigeyre M, Hervieux E, et al. Bile diversion in Roux-en-Y gastric bypass modulates sodiumdependent glucose intestinal uptake. Cell Metab. 2016;23(3):547-53 This study identifies sodium as a key factor in the glycemic control improvement after Rou-en-Y gastric bypass.

76. Bonfils PK, Taskiran M, Damgaard M, Goetze JP, Floyd AK, Funch-Jensen $\mathrm{P}$, et al. Roux-en-Y gastric bypass alleviates hypertension and is associated with an increase in mid-regional proatrial natriuretic peptide in morbid obese patients. J Hypertens. 2015;33(6):1215-25. 
77. Hallersund P, Sjostrom L, Olbers T, Lonroth H, Jacobson P, Wallenius $\mathrm{V}$, et al. Gastric bypass surgery is followed by lowered blood pressure and increased diuresis - long term results from the Swedish Obese Subjects (SOS) study. PLoS One. 2012;7(11):e49696.

78. Fandriks L. Roles of the gut in the metabolic syndrome: an overview. J Intern Med. 2017;281(4):319-36.

79. Sabbatini M, Grossini E, Molinari C, Mary D, Vacca G, Cannas M. Gastric distension causes changes in heart rate and arterial blood pressure by affecting the crosstalk between vagal and splanchnic systems in anesthetised rats. Exp Brain Res. 2017;235(4):1081-95.

80. Vijay-Kumar M, Aitken JD, Carvalho FA, Cullender TC, Mwangi $\mathrm{S}$, Srinivasan S, et al. Metabolic syndrome and altered gut microbiota in mice lacking Toll-like receptor 5. Science. 2010;328(5975):228-31.

81. Seldin MM, Meng Y, Qi H, Zhu W, Wang Z, Hazen SL et al. Trimethylamine $\mathrm{N}$-oxide promotes vascular inflammation through signaling of mitogen-activated protein kinase and nuclear factorkappaB. J Am Heart Assoc 2016;5(2). https://doi.org/10.1161/ JAHA.115.002767.

82. Fernandez-Prado R, Esteras R, Perez-Gomez MV, Gracia-Iguacel C, Gonzalez-Parra E, Sanz AB, et al. Nutrients turned into toxins: microbiota modulation of nutrient properties in chronic kidney disease. Nutrients 2017 May 12;9(5). https://doi.org/10.3390/ nu9050489.

83. Onal EM, Afsar B, Covic A, Vaziri ND, Kanbay M. Gut microbiota and inflammation in chronic kidney disease and their roles in the development of cardiovascular disease. Hypertens Res. 2019;42(2):123-40.

84. Wong J, Piceno YM, DeSantis TZ, Pahl M, Andersen GL, Vaziri ND. Expansion of urease- and uricase-containing, indole- and pcresol-forming and contraction of short-chain fatty acid-producing intestinal microbiota in ESRD. Am J Nephrol. 2014;39(3):230-7.

85. Bier A, Braun T, Khasbab R, Di Segni A, Grossman E, Haberman Y, et al. A high salt diet modulates the gut microbiota and short chain fatty acids production in a salt-sensitive hypertension rat model. Nutrients 2018 Aug 23;10(9). https://doi.org/10.3390/ nu10091154. This study supports a possible interaction among salt intake, microbiota composition, and blood pressure.

86. Miranda PM, De Palma G, Serkis V, Lu J, Louis-Auguste MP, McCarville JL, et al. High salt diet exacerbates colitis in mice by decreasing Lactobacillus levels and butyrate production. Microbiome. 2018;6(1):57 This study suggests the possibility that high salt diet may contribute to the increased prevalence and severity of autoimmune disorders by altering microbiota composition and gut immunity.

87. Zmora N, Suez J, Elinav E. You are what you eat: diet, health and the gut microbiota. Nat Rev Gastroenterol Hepatol. 2019;16(1): $35-56$.

88. de Kort S, Keszthelyi D, Masclee AA. Leaky gut and diabetes mellitus: what is the link? Obes Rev. 2011;12(6):449-58.

89. Boutagy NE, McMillan RP, Frisard MI, Hulver MW. Metabolic endotoxemia with obesity: is it real and is it relevant? Biochimie. 2016;124:11-20

90.• Kawano Y, Nakae J, Watanabe N, Kikuchi T, Tateya S, Tamori Y, et al. Colonic pro-inflammatory macrophages cause insulin resistance in an intestinal Cc12/Ccr2-dependent manner. Cell Metab. 2016;24(2):295-310 This study is the first to show that the colon is the first tissue to respond to high-fat diet, exhibiting the infiltration of pro-inflammatory macrophages and the activation of the colonic inflammasome.

91. Everard A, Belzer C, Geurts L, Ouwerkerk JP, Druart C, Bindels LB, et al. Cross-talk between Akkermansia muciniphila and intestinal epithelium controls diet-induced obesity. Proc Natl Acad Sci U S A. 2013;110(22):9066-71.
92. Dao MC, Everard A, Aron-Wisnewsky J, Sokolovska N, Prifti E, Verger EO, et al. Akkermansia muciniphila and improved metabolic health during a dietary intervention in obesity: relationship with gut microbiome richness and ecology. Gut. 2016;65(3):426-36.

93. Plovier H, Everard A, Druart C, Depommier C, Van Hul M, Geurts L, et al. A purified membrane protein from Akkermansia muciniphila or the pasteurized bacterium improves metabolism in obese and diabetic mice. Nat Med. 2017;23(1):107-13 In this paper, the safety of the treatment using $A$. muciniphila in human is shown, which is highly expected as a novel therapeutic option targeting human metabolic disorders.

94. Yang T, Santisteban MM, Rodriguez V, Li E, Ahmari N, Carvajal $\mathrm{JM}$, et al. Gut dysbiosis is linked to hypertension. Hypertension. 2015;65(6):1331-40.

95. Durgan DJ, Ganesh BP, Cope JL, Ajami NJ, Phillips SC, Petrosino $\mathrm{JF}$, et al. Role of the gut microbiome in obstructive sleep apneainduced hypertension. Hypertension. 2016;67(2):469-74.

96. Li J, Zhao F, Wang Y, Chen J, Tao J, Tian G, et al. Gut microbiota dysbiosis contributes to the development of hypertension. Microbiome. 2017;5(1):14.

97. Wilck N, Matus MG, Kearney SM, Olesen SW, Forslund K, Bartolomaeus H, et al. Salt-responsive gut commensal modulates TH17 axis and disease. Nature. 2017;551(7682):585-9.

98. Engevik MA, Aihara E, Montrose MH, Shull GE, Hassett DJ, Worrell RT. Loss of NHE3 alters gut microbiota composition and influences Bacteroides thetaiotaomicron growth. Am J Physiol Gastrointest Liver Physiol. 2013;305(10):G697-711.

99. Jose PA, Raj D. Gut microbiota in hypertension. Curr Opin Nephrol Hypertens. 2015;24(5):403-9.

100. Pluznick JL. Microbial short-chain fatty acids and blood pressure regulation. Curr Hypertens Rep. 2017;19(4):25.

101. Khalesi S, Sun J, Buys N, Jayasinghe R. Effect of probiotics on blood pressure: a systematic review and meta-analysis of randomized, controlled trials. Hypertension. 2014;64(4):897-903.

102. Galla S, Chakraborty S, Cheng X, Yeo J, Mell B, Zhang H, et al. Disparate effects of antibiotics on hypertension. Physiol Genomics. 2018;50(10):837-45.

103. Shi P, Diez-Freire C, Jun JY, Qi Y, Katovich MJ, Li Q, et al. Brain microglial cytokines in neurogenic hypertension. Hypertension. 2010;56(2):297-303.

104. Ahmed AR, Rickards G, Coniglio D, Xia Y, Johnson J, Boss T, et al. Laparoscopic Roux-en-Y gastric bypass and its early effect on blood pressure. Obes Surg. 2009;19(7):845-9.

105. Ochner CN, Gibson C, Shanik M, Goel V, Geliebter A. Changes in neurohormonal gut peptides following bariatric surgery. Int J Obes. 2011;35(2):153-66.

106. Rodriguez A, Becerril S, Valenti V, Moncada R, Mendez-Gimenez L, Ramirez B, et al. Short-term effects of sleeve gastrectomy and caloric restriction on blood pressure in diet-induced obese rats. Obes Surg. 2012;22(9):1481-90.

107. Docherty NG, Fandriks L, le Roux CW, Hallersund P, Werling M. Urinary sodium excretion after gastric bypass surgery. Surg Obes Relat Dis. 2017;13(9):1506-14.

108. Lin BY, Lin WD, Huang CK, Hsin MC, Lin WY, Pryor AD. Changes of gut microbiota between different weight reduction programs. Surg Obes Relat Dis. 2019 Jan 31. https://doi.org/10. 1016/j.soard.2019.01.026.

109. Zhang H, Pu Y, Chen J, Tong W, Cui Y, Sun F, et al. Gastrointestinal intervention ameliorates high blood pressure through antagonizing overdrive of the sympathetic nerve in hypertensive patients and rats. J Am Heart Assoc. 2014;3(5):e000929.

Publisher's Note Springer Nature remains neutral with regard to jurisdictional claims in published maps and institutional affiliations. 